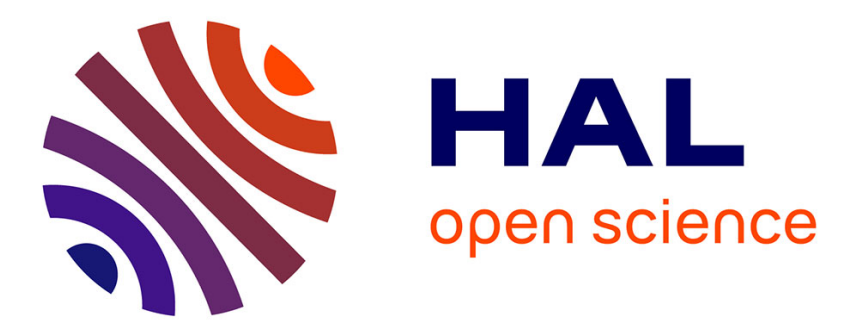

\title{
One-Dimensional Thiocyanato-Bridged Fe(II) Spin Crossover Cooperative Polymer With Unusual FeN5S Coordination Sphere
}

Kahina Nebbali, Cle Donacier Mekuimemba, Catherine Charles, Said Yefsah, Guillaume Chastanet, Antonio J. Mota, Enrique Colacio, Smail Triki

\section{To cite this version:}

Kahina Nebbali, Cle Donacier Mekuimemba, Catherine Charles, Said Yefsah, Guillaume Chastanet, et al.. One-Dimensional Thiocyanato-Bridged Fe(II) Spin Crossover Cooperative Polymer With Unusual FeN5S Coordination Sphere. Inorganic Chemistry, 2018, 57 (19), pp.12338-12346. 10.1021/acs.inorgchem.8b02061 . hal-01872926

\section{HAL Id: hal-01872926 \\ https://hal.univ-brest.fr/hal-01872926}

Submitted on 12 Sep 2018

HAL is a multi-disciplinary open access archive for the deposit and dissemination of scientific research documents, whether they are published or not. The documents may come from teaching and research institutions in France or abroad, or from public or private research centers.
L'archive ouverte pluridisciplinaire HAL, est destinée au dépôt et à la diffusion de documents scientifiques de niveau recherche, publiés ou non, émanant des établissements d'enseignement et de recherche français ou étrangers, des laboratoires publics ou privés. 


\section{One-dimensional Thiocyanato-Bridged Fe(II) Spin Crossover Cooperative Polymer With Unusual $\mathrm{FeN}_{5} \mathrm{~S}$ Coordination Sphere}

Kahina Nebbali, ${ }^{*, s}$ Cle Donacier Mekuimemba, ${ }^{\star}$ Catherine Charles, ${ }^{\ddagger}$ Said Yefsah, ${ }^{\S}$ Guillaume Chastanet, ${ }^{\dagger}$ Antonio J. Mota,${ }^{\perp}$ Enrique Colacio, ${ }^{\perp}$ Smail Triki ${ }^{\dagger *}$

*UMR-CNRS 6521, University de Brest (UBO), 6 Av. V. Le Gorgeu, C.S. 93837 - 29238 Brest Cedex 3, France. Email: smail.triki@univ-brest.fr

${ }^{\S}$ Faculté des Sciences, Université Mouloud Mammeri, Tizi-Ouzou, Algérie.

${ }^{\dagger}$ Institut de Chimie de la Matière Condensée de Bordeaux, Université de Bordeaux, 87 Av. Doc. A. Schweitzer, F-33608 Pessac, France

${ }^{\perp}$ Departamento de Química Inorgánica, Facultad de Ciencias, Universidad de Granada, Av. Fuentenueva S/N, 18071 Granada, Spain. 


\begin{abstract}
We present here a novel example of spin crossover phenomenon on a $\mathrm{Fe}(\mathrm{II})$ onedimensional chain with unusual $\mathrm{N}_{5} \mathrm{~S}$ coordination sphere. The $[\{\mathrm{Fe}(\mathrm{tpc}-\mathrm{OMe})(\mathrm{NCS})(\mu-$ $\mathrm{NCS})\}_{\mathrm{n}}$ ] (1) compound was prepared using the tridentate tpc-OMe ligand (tpc-OMe = tris(2-pyridyl)methoxymethane), $\mathrm{FeCl}_{2} \cdot 4 \mathrm{H}_{2} \mathrm{O}$ and the $\mathrm{KSCN}$ salt. Crystallographic investigations revealed that the $\mathrm{Fe}(\mathrm{II})$ ions are connected by a single bridging $\mathrm{NCS}^{-}$ ligand ( $\mu-\kappa N: \kappa S-S C N$ coordination mode) to afford a zig-zag neutral chain running along the [010] direction, in which the thiocyanato bridging groups adopt a cis head-totail configuration. The $\left(\mathrm{N}_{5} \mathrm{~S}\right)$ metal environment arises from one $\kappa \mathrm{S}-\mathrm{SCN}$ and two $\kappa \mathrm{N}$ NCS ligands, and from three pyridine of the fac-tpc-OMe tripodal ligand. This compound presents a unique extension of Fe(II) binuclear complexes into linear chains built on similar tripodal ligands and bridging thiocyanate anions. Compound 1 shows a spin crossover ( $\mathrm{SCO}$ ) behavior which has been evidenced by magnetic, calorimetric and structural investigations, revealing a shrarp cooperative spin transition with a transition temperature of $c a .199 \mathrm{~K}$. Temperature scan rate studies revealed a very narrow hysteresis loop ( $1 \mathrm{~K}$ wide). Photoswitching of this compound was also performed, evidencing a very fast relaxation process at low temperature. Among other factors, the linearity of the N-bound terminal thiocyanato ligand appears as the main structural characteristic at the origin of the presence of the SCO transition in compound $\mathbf{1}$ and in the two others $\mathrm{Fe}(\mathrm{II})$ previous systems involving thiocyanato-bridges.
\end{abstract}




\section{-INTRODUCTION}

The design of new cooperative spin crossover (SCO) materials is one of the most relevant challenges in the field of molecular materials. ${ }^{1-15}$ The SCO transition, which occurs generally for the transition metal complexes of $\mathrm{d}^{4}-\mathrm{d}^{7}$ electronic configurations, can be induced by various external perturbations, such as temperature, pressure, light, and magnetic field, yielding significant structural, magnetic and optical changes. The presence the intermolecular interactions ( $\pi$-stacking, hydrogen bonding and van der Waals contacts) in the crystal lattice can significantly affect the cooperativity which is at the origin of the presence of wide hysteresis that required for potential applications such as displays and memory, pressure and optical sensors, and spintronic devices. ${ }^{10-21}$ By far, the most studied switchable molecular materials are those based on Fe(II) transition metal ion for which the magnetic switch occurs between the paramagnetic high spin (HS) state $(\mathrm{S}=2)$ and the diamagnetic low spin $(\mathrm{LS})$ state $(\mathrm{S}=0) .{ }^{1-8}$ Until now, the majority of $\mathrm{Fe}$ (II) SCO materials involves the $\mathrm{FeN}_{6}$ coordination environment because of the appropriate ligand-field energy brought by the nitrogen-based ligands. ${ }^{1-9}$ However, in the last few years and for a relatively short time, the number of reports on $\mathrm{Fe}$ (II) SCO systems with $\mathrm{FeN}_{4} \mathrm{O}_{2}$ coordination sphere, arising from $\mathrm{N}_{4} \mathrm{O}_{2}$ hexadentate, ${ }^{22}$ $\mathrm{N}_{2} \mathrm{O}_{2}$ tetradentate ${ }^{23-29}$ or $\mathrm{N}_{2} \mathrm{O}$ tridentate ${ }^{30-32}$ Schiff-base ligands, increased in a very considerable way, and some of them exhibit remarkable SCO behaviors such as bistability around room temperature and wide hysteresis loops. ${ }^{23-29} \mathrm{Fe}$ (II) SCO complexes with other mixed donor environments for the metal active center are rare and only few of them have been structurally characterized. Among them, the following complexes should be highlighted: $\left[\mathrm{FeL}(\mathrm{CN})_{2}\right] \cdot \mathrm{xH}_{2} \mathrm{O}(\mathrm{L}=$ macrocyclic Schiff-base ligands) involving the $\mathrm{FeN}_{3} \mathrm{OC}_{2}$ and $\mathrm{FeN}_{4} \mathrm{C}_{2}$ coordination spheres; ${ }^{33-37}$ and complexes involving $\mathrm{P}$ donor atoms such as $\left[\mathrm{Fe}\left(\mathrm{PN}^{\mathrm{H}}-\mathrm{Ph}\right)_{2} \mathrm{X}_{2}\right]$ and $[\mathrm{Fe}(\mathrm{PPPP}) \mathrm{X}] \mathrm{BPh}_{4}\left(\mathrm{PN}^{\mathrm{H}}-\mathrm{Ph}=\mathrm{N}-\right.$ diphenylphosphino-2-aminopyridine, $\quad \mathrm{PPPP}=$ 1,4,7,10-tetraphenyl-1,4,7,10tetraphosphadecane, $\mathrm{X}=\mathrm{Cl}, \mathrm{Br})$ and $\left[\mathrm{Fe}(\mathrm{tppb}) \mathrm{Br}_{2}\right]_{\mathrm{n}} \quad(\operatorname{tppb}=1,2,4,5-$ tetrakis(diphenylphosphanyl)benzene) exhibiting $\mathrm{FeN}_{2} \mathrm{P}_{2} \mathrm{X}_{2}$ and $\mathrm{FeP}_{4} \mathrm{X}_{2}$ coordination environments, respectively. ${ }^{38-40}$ More recently, other SCO systems with mixed N/S donor atoms have been reported and structurally characterized. ${ }^{41-45}$ Among them, mononuclear or dinuclear complexes based on thioether ligands, with $\mathrm{FeN}_{4} \mathrm{~S}_{2}$ coordination sphere, have been shown to exhibit original transitions such as multi-step cooperative SCO behaviour. ${ }^{41-44}$ Concerning Fe(II) complexes with $\mathrm{FeN}_{5} \mathrm{~S}$ coordination sphere, very few examples have been investigated, ${ }^{45-49}$ and to the best of our knowledge, 
only one example, $\left[\{\mathrm{Fe}(\mathrm{tpc}-\mathrm{OH})(\mathrm{NCS})(\mu-\mathrm{NCS})\}_{2}\right](\mathrm{PrOH})_{2} \quad(2)$, exhibits a SCO behaviour. ${ }^{45}$ The latter is a dinuclear SCO Fe(II) complex based on the tripodal ligand tris(2-pyridyl)methanol (see scheme $1, \mathrm{R}=\mathrm{H}$ ) for which the $\mathrm{Fe}(\mathrm{II})$ ions are connected by a pair of end-to-end thiocyanato bridges $(\mu-\kappa N: \kappa S-S C N$ coordination mode) in a head-to-tail configuration. ${ }^{45}$ Very recently, we enriched this uncommon Fe(II) dinuclear system by a second example, $\left[\{\mathrm{Fe}(\mathrm{tpc}-\mathrm{Obn})(\mathrm{NCS})(\mu-\mathrm{NCS})\}_{2}\right](3)$, based on nearly similar tripodal ligand (see Scheme1, $\mathrm{R}=\mathrm{C}_{6} \mathrm{H}_{5}$ ), but for which the magnetic studies indicated the occurrence of ferromagnetic interactions and the absence of any SCO transition. ${ }^{46}$

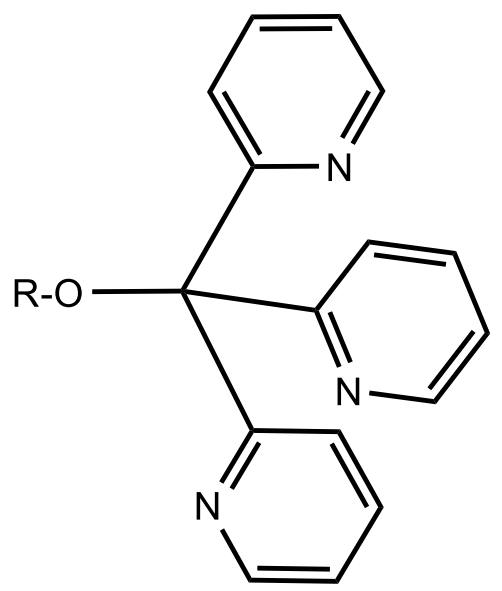

Scheme 1. Substituted tris(2-pyridyl)methane ligands (tpc-OR, with $\mathrm{R}=\mathrm{H}$, Me, $\left.\mathrm{C}_{6} \mathrm{H}_{5}, \ldots\right)$.

In this context, we report in the present work, the synthesis, crystal structures, differential scanning calorimetry (DSC), magnetic properties and MO extended-Hückel calculations of the $\left[\{\mathrm{Fe}(\mathrm{tpc}-\mathrm{OMe})(\mathrm{NCS})(\mu-\mathrm{NCS})\}_{\mathrm{n}}\right] \quad($ tpc-OMe $=\operatorname{tris}(2-$ pyridyl)benzyloxymethane) complex (1), as the first SCO 1-D coordination polymer exhibiting an unusual $\mathrm{FeN}_{5} \mathrm{~S}$ coordination sphere. The structure-properties relationship of this compound has been discussed on the basis of MO extended-Hückel calculations and on the two previous compounds, $\mathbf{2}$ and $\mathbf{3}$, based on similar tripodal ligands and endto-end thiocyanato bridges.

\section{- RESULTS AND DISCUSSION}

Synthesis. The tris(2-pyridyl)metoxymethane (tpc-OMe) ligand was synthesized according to the previously described method (see Figures S1, S2 and S3). ${ }^{50}$ The crystalline powder of compound $\mathbf{1}$ was synthesized by adding slowly an acetonitrile solution of $\mathrm{K}(\mathrm{NCS})$ to a methanolic solution of $\mathrm{FeCl}_{2} \cdot 4 \mathrm{H}_{2} \mathrm{O}$ and tris(2pyridyl)methoxymethane (tpc-OMe) in 2:1:1 ratio, respectively. The single crystals of 1 
have been prepared using diffusion technique in glass tube $(3.0 \mathrm{~mm}$ diameter) by delicately layering a methanolic solution of $\mathrm{K}(\mathrm{NCS})$ onto a methanolic solution containing $\mathrm{FeCl}_{2} \cdot 4 \mathrm{H}_{2} \mathrm{O}$ and tris(2-pyridyl)methoxymethane.

Crystal structure description. Based on the conclusions derived from the thermal variation of the magnetic data and from the Differential Scanning Calorimetry (DSC) measurements (see below), the crystal structure of $\left[\{\mathrm{Fe}(\mathrm{tpc}-\mathrm{OMe})(\mathrm{NCS})(\mu-\mathrm{NCS})\}_{\mathrm{n}}\right](\mathbf{1})$ was determined at 296 and $150 \mathrm{~K}$. The unit cell parameters, derived at these two temperatures, indicate the absence of any structural transition within the studied temperature range. Compound 1 crystallizes in the monoclinic system with a $P 2_{1} / n$ space group. Crystal data, bond lengths and bond angles are given in Tables S1 and S2. The following general structural description for $\mathbf{1}$ is relative to the room temperature data (296 K). The pertinent structural change induced by the thermal variation will be discussed in the section devoted to the magneto-structural relationships. The asymmetric unit of 1, depicted in Figure 1, consists of one Fe(II) ion, one tpc-OMe and two thiocyanato ligands, all located on general positions. The molecular structure of 1 can be described as a regular zig-zag neutral chain running along the [010] direction, in which one of the two $\mathrm{NCS}^{-}$anions act as a $\mu_{2}$-bridging ligand $(\mu-\kappa \mathrm{N}: \kappa \mathrm{S}-\mathrm{SCN})$ (Figure $1)$.

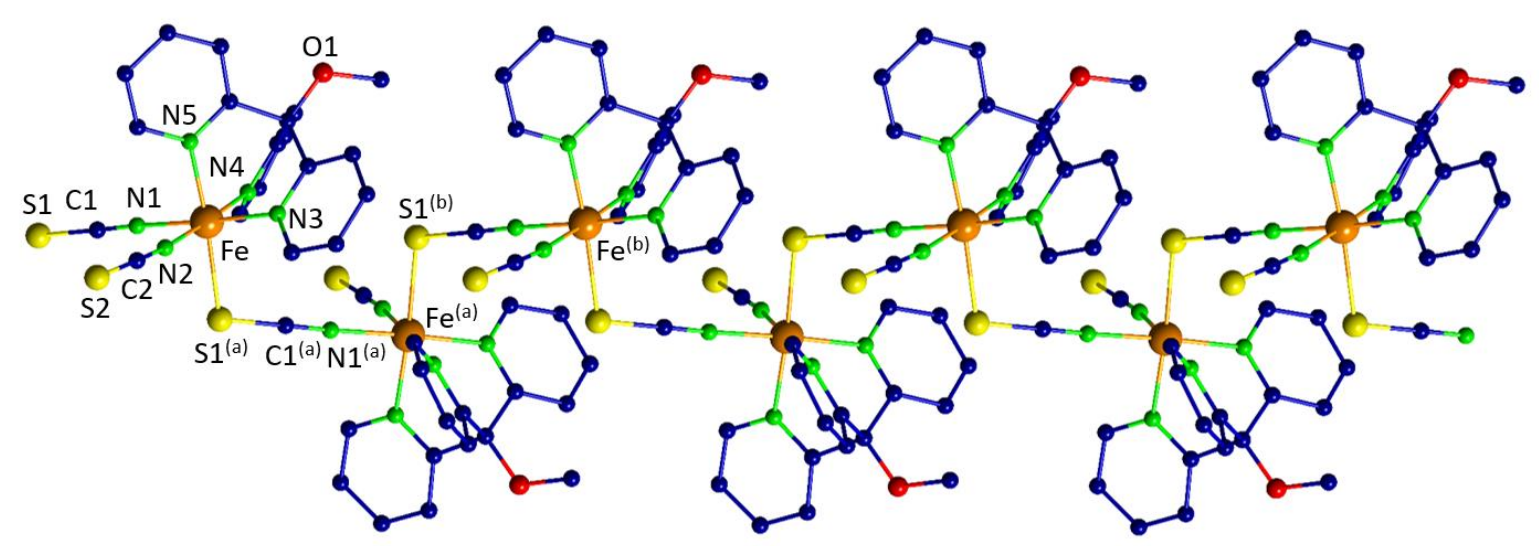

Figure 1. View of the 1-D covalent neutral chain of $\mathbf{1}$ along the [010] direction and the local environments for Fe(II). Codes of equivalent positions: (a) 1/2-x, 1/2+y, 1/2-z ; (b): $\mathrm{x}, 1+\mathrm{y}, \mathrm{z}$.

Within the covalent molecular neutral chain, the iron(II) metal ion exhibits a distorted $\mathrm{FeN}_{5} \mathrm{~S}$ polyhedron, arising from the coordination of the three pyridine nitrogen atoms of the tpc-OMe ligand (N4, N3 and N5), and from the two nitrogen (N1 and N2) and the 
sulphur $\left(\mathrm{S}^{(\mathrm{a})}\right)$ atoms, belonging to the two equivalent bridging (see Figure 1: Fe-N1$\mathrm{C} 1-\mathrm{S} 1$ and $\left.\mathrm{Fe}-\mathrm{S} 1^{(\mathrm{a})}-\mathrm{C} 1^{(\mathrm{a})}-\mathrm{N} 1^{(\mathrm{a})}\right)$ and to the terminal thiocyanato $(\mathrm{Fe}-\mathrm{N} 2-\mathrm{C} 2-\mathrm{S} 2)$ ligands. At room temperature, the three Fe-Npyr distances in the 2.165-2.213 $\AA$ range, are significantly longer than the $\mathrm{Fe}-\mathrm{N}$ distances corresponding to the terminal (Fe-N2:

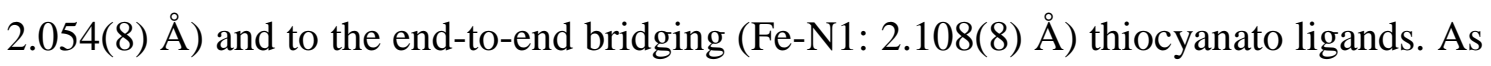
expected, the Fe-S (2.573(3) $\AA$ ) is the longest distance around $\mathrm{Fe}(\mathrm{II})$ ion and the intrachain $\mathrm{Fe} \cdot \mathrm{F}$ Fe distance is 5.971(2) $\AA$. The bond angles deviate considerably from ideal values as demonstrated by the high value of the distortion parameter $(\Sigma)^{51}$ depicted in table 1.

Table 1. Selected bond lengths $(\AA)$ and bond angles $\left(^{\circ}\right)$ in compound 1 at $296 \mathrm{~K}$.

\begin{tabular}{|c|c|c|c|}
\hline Fe-N1 & $2.108(8)$ & Fe-N4 & $2.179(7)$ \\
\hline $\mathrm{Fe}-\mathrm{N} 2$ & $2.054(8)$ & Fe-N5 & $2.213(7)$ \\
\hline $\mathrm{Fe}-\mathrm{N} 3$ & $2.174(7)$ & $\mathrm{Fe}-\mathrm{S} 1^{\text {(a) }}$ & $2.573(3)$ \\
\hline $\mathrm{Fe} \ldots \mathrm{Fe}^{(\mathrm{a})}$ & $5.971(2)$ & & \\
\hline $\mathrm{N} 1-\mathrm{Fe}-\mathrm{N} 2$ & $94.5(3)$ & $\mathrm{N} 2-\mathrm{Fe}-\mathrm{S} 1^{(\mathrm{a})}$ & $87.8(2)$ \\
\hline N1-Fe-N3 & $168.8(3)$ & $\mathrm{N} 3-\mathrm{Fe}-\mathrm{N} 4$ & 79.4(3) \\
\hline N1-Fe-N4 & $91.4(3)$ & N3-Fe-N5 & $83.2(3)$ \\
\hline N1-Fe-N5 & $89.4(3)$ & $\mathrm{N} 3-\mathrm{Fe}-\mathrm{S} 1^{(\mathrm{a})}$ & $99.4(2)$ \\
\hline $\mathrm{N} 1-\mathrm{Fe}-\mathrm{S} 1^{(\mathrm{a})}$ & $88.1(2)$ & N4-Fe-N5 & $84.0(3)$ \\
\hline N2-Fe-N3 & $94.1(3)$ & $\mathrm{N} 4-\mathrm{Fe}-\mathrm{S} 1^{(\mathrm{a})}$ & $97.4(2)$ \\
\hline $\mathrm{N} 2-\mathrm{Fe}-\mathrm{N} 4$ & $172.2(3)$ & $\mathrm{N} 5-\mathrm{Fe}-\mathrm{S} 1^{(\mathrm{a})}$ & $177.2(2)$ \\
\hline N2-Fe-N5 & $91.1(3)$ & $\Sigma(\mathrm{Fe}) /{ }^{\circ}$ & 56.0 \\
\hline
\end{tabular}

Symmetry transformations used to generate equivalent atoms: (a) : 1/2-x, 1/2+y, 1/2-z; $\Sigma$ is the sum of the deviation from $90^{\circ}$ of the 12 cis-angles of the $\mathrm{FeN}_{5} \mathrm{~S}$ octahedron. ${ }^{51}$

Examination of the crystal packing in $\mathbf{1}$ reveals that the shortest intermolecular distances correspond to the $\pi$-stacking contacts between the pyridine groups of two adjacent chains. As shown in Figure 2, two $\pi-\pi$ contacts between the tpc-OMe ligands of adjacent chains, connect the 1-D chains along the $a-c$ and the $a+c$ crystallographic directions, leading to an overall 3-D packing. 


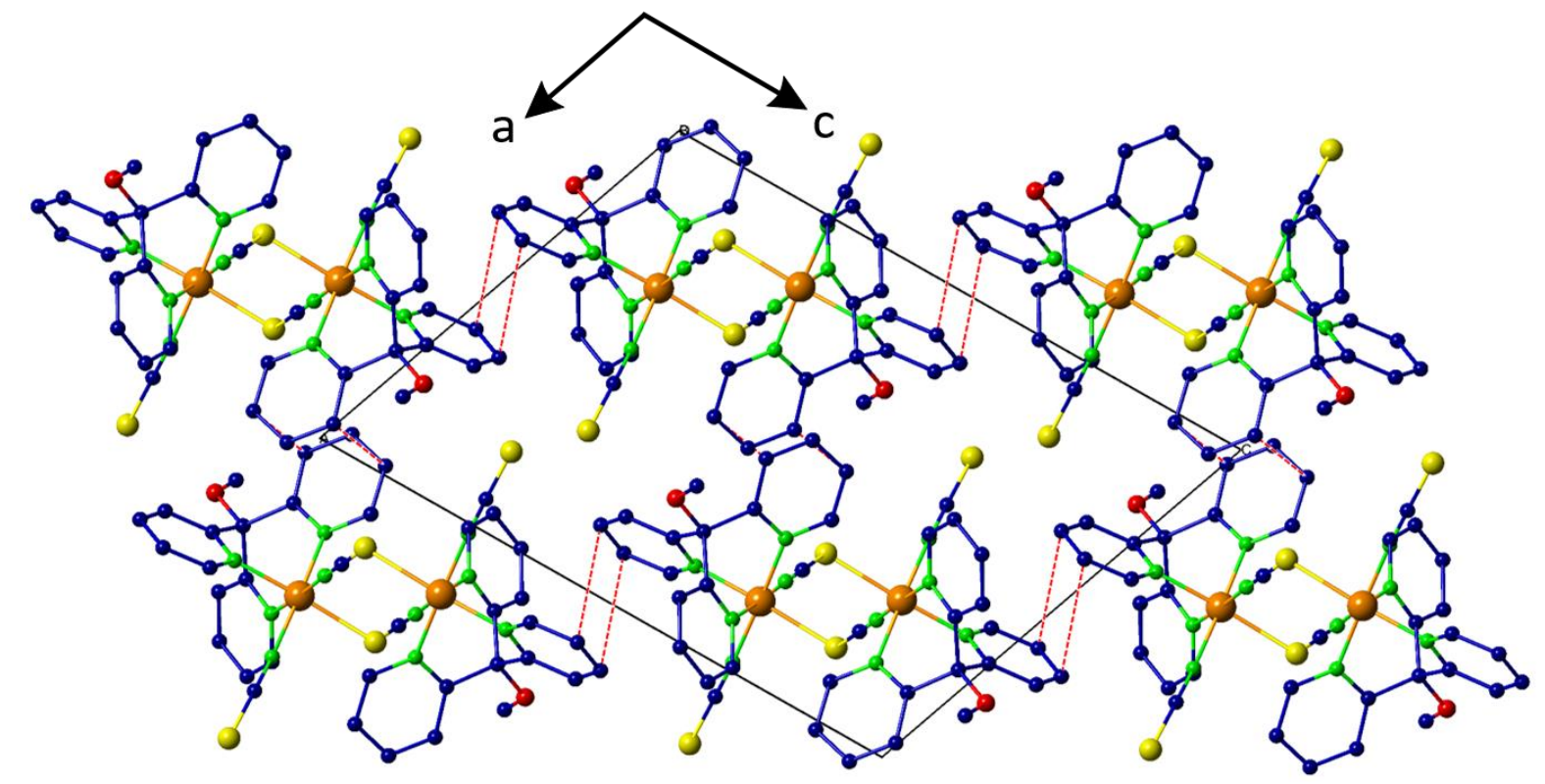

Figure 2. 3-D Packing of $\mathbf{1}$ in the $a c$ plane showing the shortest $\pi$ - $\pi$ contacts between the pyridine groups (see red dashed lines) of adjacent chains running along the $a-c$ (C...C $3.714 \AA$ ) and the $a+c$ (C...C $3.599 \AA$ ) directions.

Magnetic and calorimetric characterizations. To characterize the thermal behavior of 1, polycrystalline powder has been used. The room-temperature X-ray powder diffraction pattern (XRPD) of this powder has been recorded to confirm its isomorphism with the single crystal phase. The measured pattern of microcrystalline powder of $\mathbf{1}$ is similar to the pattern derived from the single-crystal data (Figure 3). Chemical analysis on this powder, showed a very good agreement with the expected values for the $\mathrm{CHN}$ elemental analyses (see experimental section). The absence of any amorphous impurities in the crystalline powder was confirmed by IR spectroscopy which showed that the spectrum of the single crystals is similar to that measured for the crystalline powder of $\mathbf{1}$ (see Figures $\mathrm{S} 4 \mathrm{a}$ and $\mathrm{S} 4 \mathrm{~b}$ ). The infrared spectrum of $\mathbf{1}$ displays two strong absorption bands at 2104(s) and 2069(s) $\mathrm{cm}^{-1}$. The first band can be assigned to the bridging coordination mode of the $\mathrm{NCS}^{-}$group $(\mu-\kappa \mathrm{N}: \kappa \mathrm{S}-\mathrm{SCN})$, where the second one is assigned to the terminal coordination mode $(\kappa \mathrm{N}-\mathrm{SCN}) .{ }^{52}$ 


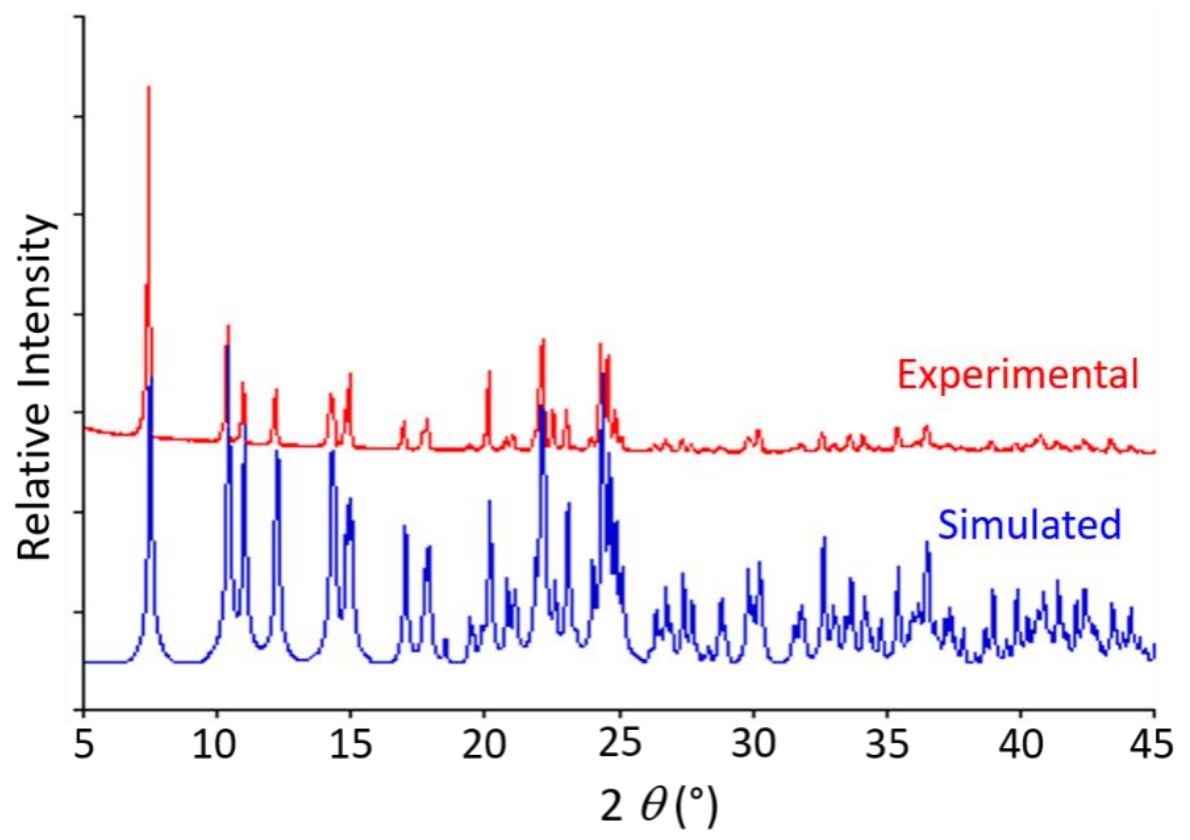

Figure 3. Observed and calculated X-ray powder diffraction patterns for $[\{\mathrm{Fe}(\mathrm{tpc}-$ $\left.\mathrm{OMe})(\mathrm{NCS})(\mu-\mathrm{NCS})\}_{\mathrm{n}}\right](\mathbf{1})$.

The thermal variation of the $\chi_{M} T$ product for compound 1 in the temperature range 10$350 \mathrm{~K}\left(\chi_{M}=\right.$ the molar magnetic susceptibility per one $\mathrm{Fe}(\mathrm{II})$ ion $)$ under a magnetic field of $10 \mathrm{kOe}$ is shown in Figure $4 \mathrm{a}$. At room temperature, the value of the $\chi_{M} T$ product of $3.56 \mathrm{~cm}^{3} \cdot \mathrm{K} \cdot \mathrm{mol}^{-1}$ agrees well with the value expected for a magnetically isolated HS $(S$ =2) $\mathrm{Fe}(\mathrm{II})$ ion with $g=2.18$. Upon cooling, the $\chi_{M} T$ value remains relatively constant up to $c a .250 \mathrm{~K}$ and then sharply decreases reaching a value of $0.06 \mathrm{~cm}^{3} \cdot \mathrm{K} \cdot \mathrm{mol}^{-1}$ at 10 $\mathrm{K}$, indicating the occurrence of a complete and abrupt HS/LS transition with a transition temperature of $199 \mathrm{~K}$. This behavior is in excellent agreement with the DSC studies for which the thermal dependence of the heat flow reveals exo- and the endo-thermic transitions with maxima at $198 \mathrm{~K}$ and $199 \mathrm{~K}$, respectively (Figure 4b). From these calorimetric data, a $\Delta H$ value of $7.87 \mathrm{~kJ} \mathrm{~mol}^{-1}$ can be extracted. Assuming that $\Delta S=\Delta H$ $/ T_{1 / 2}$, the variation of entropy could be calculated as equal to $39.6 \mathrm{~J} \mathrm{~mol}^{-1} \mathrm{~K}^{-1}$. Using these values and adding a cooperative parameter $\Gamma=2.75 \mathrm{~kJ} \mathrm{~mol}^{-1}$, a very reasonable simulation of the thermal SCO curve can be obtained (inset Figure 4a) using the Slichter and Drickamer model. ${ }^{53}$ 

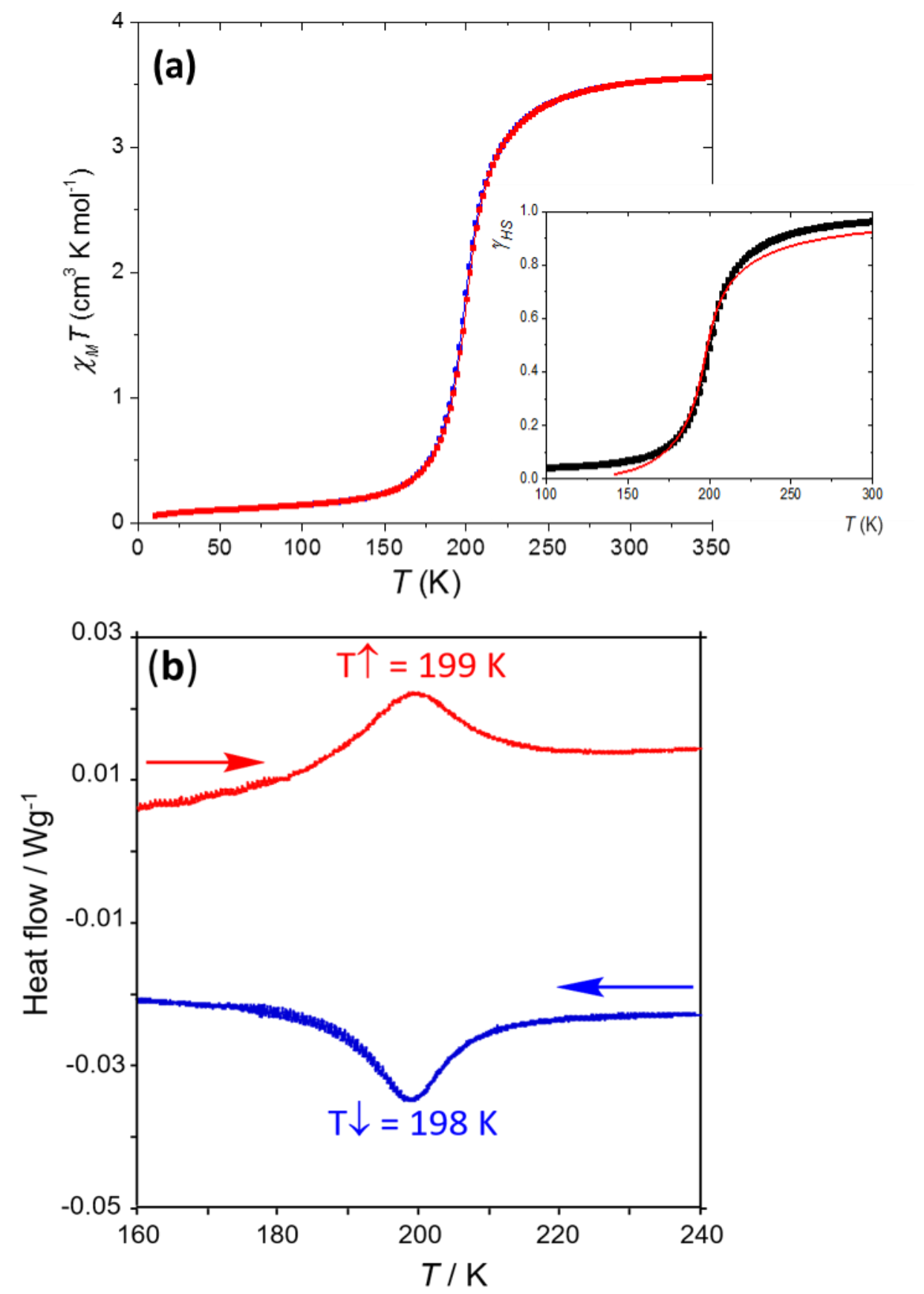

Figure 4. (a) Thermal variation of the $\chi_{M} T$ product for 1 showing the abrupt incomplete spin transition at $199 \mathrm{~K}\left(\mathrm{scan}\right.$ rate $\left.=0.8 \mathrm{~K} \cdot \mathrm{min}^{-1}\right)$. The inset reports the Slichter \& Drickamer fit (red line) as discussed in the text. (b) DSC study for $\mathbf{1}$ (scan rate $=0.8$ $\mathrm{K} \cdot \mathrm{min}^{-1}$ ) revealing the exo- and the endo-thermic transitions with maxima at $198 \mathrm{~K}$ and $199 \mathrm{~K}$, respectively. These values, derived from the maximum of the DSC peaks, are in good agreement with the transition temperature ( $c$. $199 \mathrm{~K}$ ) derived from magnetic data. 
Since DSC studies showed a narrow hysteresis loop $\left(T_{1 / 2}^{u p}=199\right.$ and $\left.T_{1 / 2}{ }^{\text {down }}=198 \mathrm{~K}\right)$, we have investigated the evolution this hysteresis loop, as a function of the scan rate, using magnetic and calorimetric characterizations, to confirm the bistable character of $\mathbf{1}$. The magnetic characterizations clearly show that both transition temperatures (in the cooling and warming scans) are dependent on the scan rate (Figure 5).
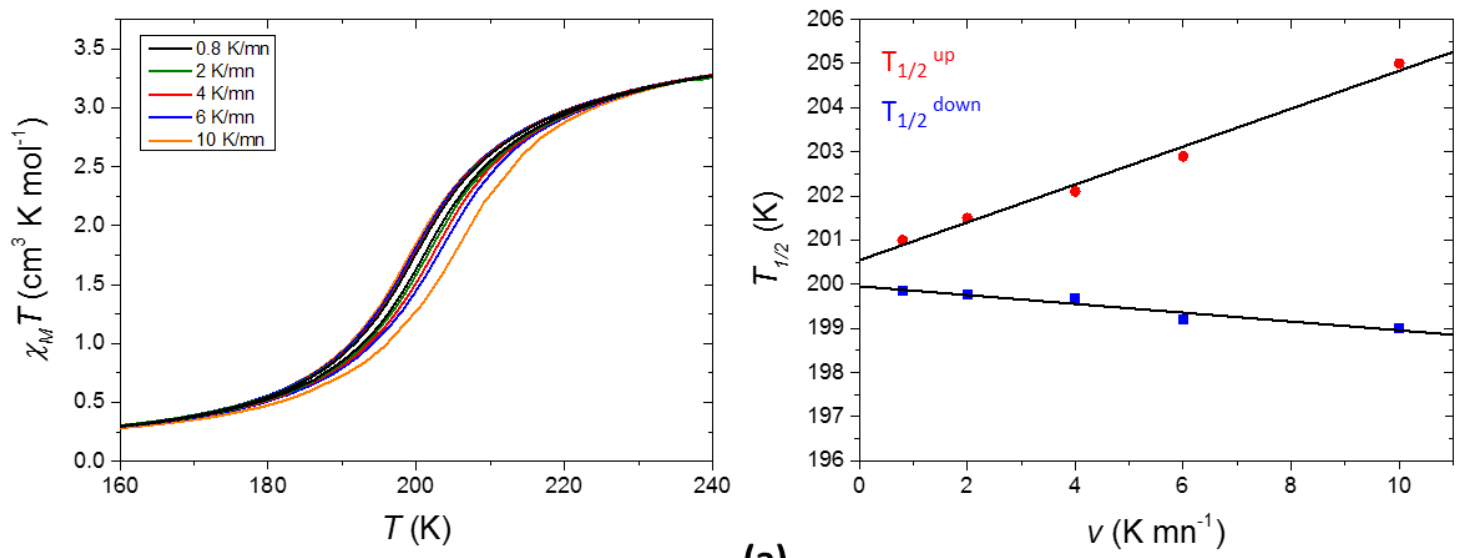

(a)
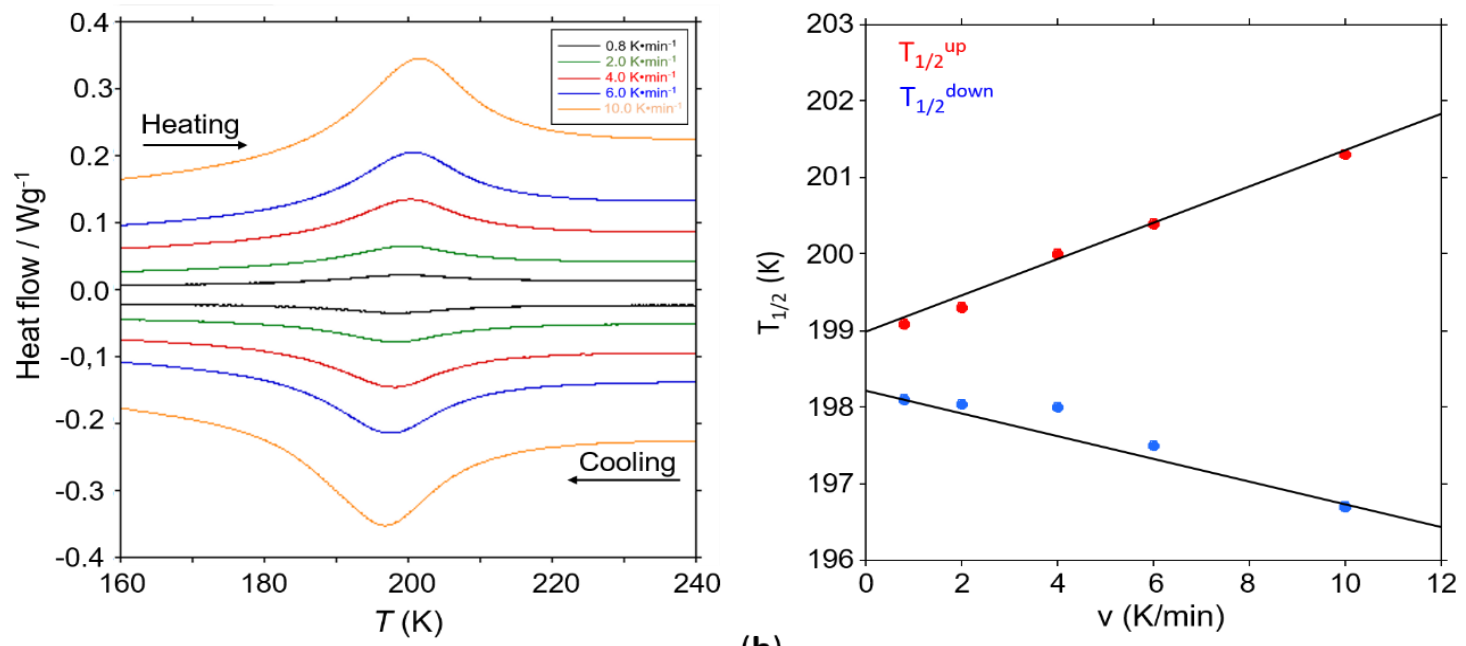

(b)

Figure 5. Hysteresis loops of the SCO transition at different scan rates in the range 0.8$10 \mathrm{~K} / \mathrm{min}$, indicating the dependence of both transition temperatures $\left(T_{1 / 2}{ }^{\text {down }}\right.$ and $\left.T_{1 / 2}^{\text {up }}\right)$ and the hysteresis width $(\Delta T)$ with the scan rate: magnetic (a) and DSC (b) measurements.

When the scan rate varies from 0.8 to $10 \mathrm{~K} / \mathrm{min}$, the transition temperature varies from 199.9 $\mathrm{K}$ to $199.0 \mathrm{~K}$ in the cooling mode, and from 201 to $205 \mathrm{~K}$ for the warming mode (Figure 5a). This magnetic bistability was confirmed by DSC studies (see Figure 5b) 
that reveal exo- and endo-thermic transitions with similar variation when the scan rate varies from 0.8 to $10 \mathrm{~K} / \mathrm{min}\left(T_{1 / 2}^{\text {down }}\right.$ from 198.1 to $196.7 \mathrm{~K} ; T_{1 / 2}^{\text {up }}$ from 199.1 to 201.3 K). As clearly shown in Figure 5, the two transition temperatures vary linearly with the scan rate, indicating a hysteresis width of less than $1 \mathrm{~K}$ at infinitely slow temperature scan rate, with an error of $0.3 \mathrm{~K}$ in the linear fit. Let us note that, despite different physical characterizations and sample preparations between magnetic and DSC measurements, the discrepancy between the related $T_{1 / 2}$ values are rather small.

LIESST effect was attempted on compound 1. Different wavelengths between 405 and $980 \mathrm{~nm}$ were tested and $510 \mathrm{~nm}$ appeared to induce an increase of the magnetic response. However, this increase is very small. Whatever the fluence used from 5 to 35 $\mathrm{mW} / \mathrm{cm}^{2}$ on the sample, the photoconversion efficiency did not exceed $10 \%$. Moreover, when light was switched off, a very rapid decrease of the magnetic signal was observed since in less than one minute the initial value was recovered (Figure 6). This indicates a very fast relaxation process of the photo-induced state.

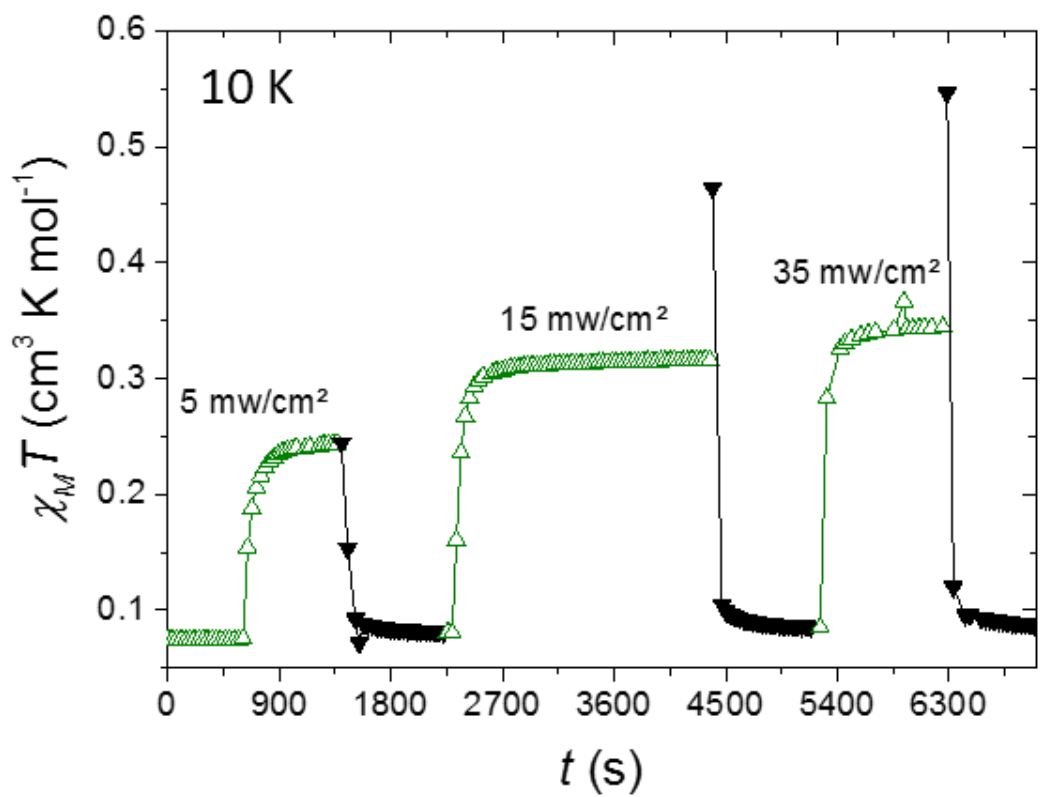

Figure 6. Irradiation $(\Delta)$ of sample 1 at $10 \mathrm{~K}$ at different light fluences; followed by relaxation in the dark $(\boldsymbol{\nabla})$.

Magneto-structural relationships. Based on the transition temperature derived from the magnetic and the DSC data, the crystal structure of $\mathbf{1}$ has been determined at $150 \mathrm{~K}$. Since the average value of the Fe-L distances (Fe-N and Fe-S in the case of compound 1) and the distortion parameter $(\Sigma)$ are highly sensitive to the $\mathrm{Fe}(\mathrm{II})$ spin state, both 
parameter will be used in this section to assign the spin state on the $\mathrm{Fe}$ (II) crystallographic centers. Table 2 lists the Fe-N and Fe-S bond lengths observed for compound 1, and for $\left[\{\mathrm{Fe}(\mathrm{tpc}-\mathrm{OH})(\mathrm{NCS})(\mu-\mathrm{NCS})\}_{2}\right](\mathrm{PrOH})_{2} \quad(\mathbf{2})^{45}$ and $[\{\mathrm{Fe}(\mathrm{tpc}-$ Obn $\left.)(\mathrm{NCS})(\mu-\mathrm{NCS})\}_{2}\right](3) ;{ }^{46}$ two discrete dinuclear examples (see Scheme 2) involving similar ligands than those of compound $\mathbf{1}$, and $\mathrm{FeN}_{5} \mathrm{~S}$ distorted octahedral geometry.

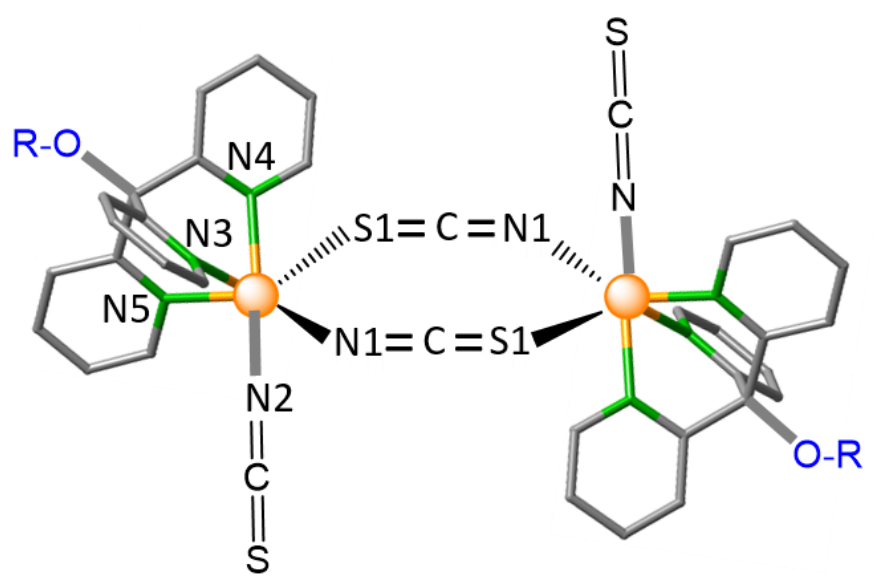

Scheme 2. Schematic representation of $\left[\{\mathrm{Fe}(\mathrm{tpc}-\mathrm{OH})(\mathrm{NCS})(\mu-\mathrm{NCS})\}_{2}\right](\mathrm{PrOH})_{2}{ }^{45}(\mathbf{2}, \mathrm{R}$ $=\mathrm{H})$ and $\left[\{\mathrm{Fe}(\mathrm{tpc}-\mathrm{Obn})(\mathrm{NCS})(\mu-\mathrm{NCS})\}_{2}\right]^{46}\left(\mathbf{3}, \mathrm{R}=\mathrm{bn}=\mathrm{C}_{6} \mathrm{H}_{5}\right)$.

Table 2. Comparison of selected Fe-N and Fe-S distances ( $\AA$ ) in $\mathbf{1}$ and in two other examples containing the $\left[\mathrm{Fe}_{2}(\mu-\mathrm{SCN})_{2}\right]$ fragment and the $\mathrm{FeN}_{5} \mathrm{~S}$ octahedral environment.

\begin{tabular}{|c|c|c|c|c|c|}
\hline & \multicolumn{2}{|c|}{1} & \multicolumn{2}{|c|}{$2^{45}$} & \multirow{2}{*}{$\begin{array}{c}\mathbf{3}^{46} \\
\mathrm{HS} / 170 \mathrm{~K}\end{array}$} \\
\hline $\begin{array}{l}\text { Spins state } \\
\text { / T }\end{array}$ & HS / 296K & $\mathrm{LS} / 150 \mathrm{~K}$ & HS / $296 \mathrm{~K}$ & LS / $100 \mathrm{~K}$ & \\
\hline Fe1-N1 & $2.108(8)$ & $1.949(3)$ & $2.105(5)$ & $1.941(2)$ & $2.108(4)$ \\
\hline Fe1-N2 & $2.054(8)$ & $1.946(4)$ & $2.062(5)$ & $1.948(2)$ & $2.054(4)$ \\
\hline Fe1-N3 & $2.174(7)$ & $1.976(3)$ & $2.169(4)$ & $1.966(2)$ & $2.237(3)$ \\
\hline Fe1-N4 & $2.179(7)$ & $1.967(3)$ & $2.195(4)$ & $1.969(2)$ & $2.165(3)$ \\
\hline Fe1-N5 & $2.213(7)$ & $1.993(3)$ & $2.167(4)$ & $1.957(2)$ & $2.173(3)$ \\
\hline $\mathrm{Fe} 1-\mathrm{S} 1$ & $2.573(3)$ & $2.377(2)$ & $2.607(2)$ & $2.397(1)$ & $2.605(2)$ \\
\hline$\langle\mathrm{Fe}-\mathrm{N}\rangle$ & $2.146(8)$ & $1.966(4)$ & $2.140(5)$ & $1.956(2)$ & $2.147(4)$ \\
\hline \multirow[t]{2}{*}{${ }^{\mathrm{a}} \Sigma(\mathrm{Fe}) /{ }^{\circ}$} & 56.0 & 28.7 & 78.0 & 14.0 & 49.0 \\
\hline & \multicolumn{2}{|c|}{ SCO behavior, $T_{1 / 2}=199 \mathrm{~K}$} & \multicolumn{2}{|c|}{ SCO behavior, $T_{1 / 2}=207 \mathrm{~K}$} & $\begin{array}{l}\text { HS / Ferromagnetic } \\
\text { with } J=+1.08 \mathrm{~cm}^{-1}\end{array}$ \\
\hline
\end{tabular}

${ }^{\mathrm{a}} \Sigma=$ the sum of the deviation from $90^{\circ}$ of the 12 cis-angles of the $\mathrm{FeN}_{5} \mathrm{~S}$ octahedron. ${ }^{51}$ tpc-OH $=$ tris(2-pyridyl)metanol, tpc-Obn = tris(2-pyridyl)benzyloxymethane. 
At room temperature $(296 \mathrm{~K})$ the average value of the five Fe-N (2.146(8) $\AA$ ) and Fe-S (2.573(3) $\AA$ ) distances of $\mathbf{1}$ (Table 2) are in good agreement with those observed for the $\mathrm{HS} \mathrm{Fe}(\mathrm{II})$ ion in a $\mathrm{FeN}_{5} \mathrm{~S}$ octahedral environment. The two dinuclear complexes ( 2 and 3), depicted in scheme 2, display $\mathrm{FeN}_{5} \mathrm{~S}$ distorted geometry, similar to that observed for compound 1, with systematically Fe-N(py) distances (Fe-N3, Fe-N4 and Fe-N5) significantly longer than the Fe-N distances corresponding to the bridging (Fe-N1) and terminal thiocyanato (Fe-N2) ligands. This deformation is stressed by the length of the Fe-S bond and by the bond angles which deviate considerably from ideal values, as demonstrated by the values of the $\Sigma$ distortion parameters summarized in table 2 for the three complexes. The crystal structure determined at $150 \mathrm{~K}$ reveals, as expected, significant changes since the five Fe-N and Fe-S distances of $\mathbf{1}$ are substantially smaller $(<\mathrm{Fe}-\mathrm{N}\rangle=1.966(4) \AA ; \mathrm{Fe}-\mathrm{S}=2.377(2) \AA)$, indicating the presence of a LS state of the $\mathrm{Fe}(\mathrm{II})$ ion. However, the three Fe-N(py) and the two Fe-N(NCS) distances do not show significant difference for the LS state for $\mathbf{1}$ and 2, leading to much less distorted $\mathrm{FeN}_{5} \mathrm{~S}$ environments, in agreement with lower $\Sigma$ distortion parameters. The variation of $\Sigma$ between the HS and LS in $\mathbf{1}$ is rather small $\left(27^{\circ}\right)$ which could explain the weak lifetime of the photo-induced state in this compound. Compound 2, however, that present a rather large $\Delta \Sigma\left(64^{\circ}\right)$ could exhibit light-induced metastable HS state with a longer lifetime than in $\mathbf{1}$.

Finally, a question arises concerning the magnetic behaviour of complexes 1-3: Why 1 and 2 exhibit SCO behaviours, whereas 3 remains in the HS state in the 300-2 K temperature range? First, one could think, in answer to this question that the cooperative effect along the chain could favour the existence of SCO behaviour in compound $\mathbf{1}$. However, this hypothesis can be ruled out as compound $\mathbf{2}$ having a dinuclear structure also exhibits SCO behaviour with a $\mathrm{T}_{1 / 2}=207 \mathrm{~K}$, which is very close to that observed for 1. A more appropriate answer to the above question is based on the Fe-N-C angle of the terminal N-bound thiocyanate group. In a previous work, and based on theoretical ligand field calculations on $\mathrm{Ni}(\mathrm{II})-\mathrm{N}$-bound thiocyanate complexes, some of us suggested that, among other factors, the bent N-bound terminal thiocyanato ligand promotes a weaker ligand field on the $\mathrm{Fe}(\mathrm{II})$ ion than the linear configuration. ${ }^{46}$ So, the former configuration would favours the HS state, whereas the latter, the SCO transition. The fact that compound $\mathbf{1}$ containing almost a linear N-bound terminal thiocyanato ligand (Fe-N-C of 172.3 and $174.7^{\circ}$ at $296 \mathrm{~K}$ and $150 \mathrm{~K}$, respectively) exhibits SCO 
behaviour seems to support this conclusion. In order to gain insight on the effect of $\mathrm{N}$ $\mathrm{C}-\mathrm{S}$ bent angle of the N-bound terminal thiocyanate group on the crystal ligand field in these head to tail single and double thiocyanato-bridged $\mathrm{Fe}(\mathrm{II})$ complexes with $\mathrm{FeN}_{5} \mathrm{~S}$ coordination sphere, we have carried out simple MO extended-Hückel calculations on the model given in Figure 7. This model derives from the structure of $\mathbf{1}$ by changing the pyridine moieties of the ligand by ammonia molecules and varying the $\mathrm{N}-\mathrm{C}-\mathrm{S}$ angle of the N-bound terminal group $(\alpha)$ between $180^{\circ}$ (linear thiocyanate) and $90^{\circ}$. As expected, the energy gap $(\Delta)$ between the highest energy $d$ orbital arising from the $t_{2 \mathrm{~g}}$ set in a hypothetical octahedral geometry $\left(d_{\mathrm{xy}}\right)$ and the lowest energy $d$ orbital arising from the $e_{\mathrm{g}}$ set $\left(d_{\mathrm{z} 2}\right)$ decreases as the $\alpha$ angle diminishes (see Figure 7). For the $\alpha$ value observed for the dinuclear complex $\left[\{\mathrm{Fe}(\mathrm{tpc}-\mathrm{Obn})(\mathrm{NCS})(\mu-\mathrm{NCS})\}_{2}\right]\left(156.6^{\circ}\right)$ a slight but significant reduction of the crystal ligand field is calculated $\left(\sim 70 \mathrm{~cm}^{-1}\right)$, which would favour the HS configuration found for this complex. ${ }^{46}$ We have also studied the variation of the Fe-S-CN angle of the thiocyanate bridge between $102.7^{\circ}$ (the experimental value at $296 \mathrm{~K})$ and $180^{\circ}$ (linear) and the change in the energy gap $(\Delta)$ was only of $11.7 \mathrm{~cm}^{-1}$.

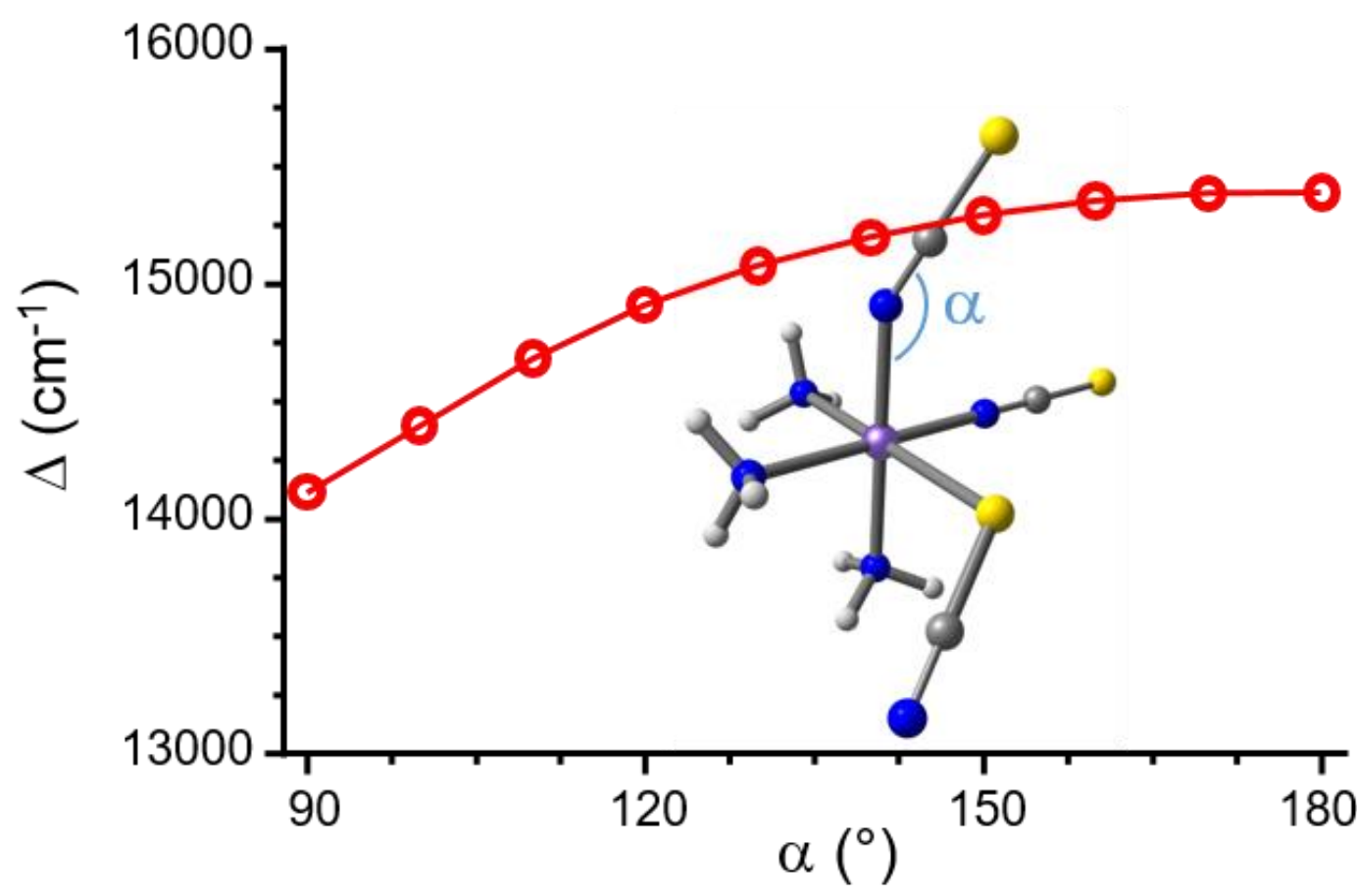

Figure 7. Ligand field variation with the Fe-N-CS angle of the terminal N-bound thiocyanato group. Inset: Model compound used in MO-EH calculations. 
This result indicates that for these $\left[\{\mathrm{Fe}(\mathrm{tpc}-\mathrm{OR})(\mathrm{NCS})(\mu-\mathrm{NCS})\}_{2}\right]$ complexes with similar Fe-N and Fe-S distances, the Fe-N-C angle of terminal N-bound thiocyanato group seems to be the most important structural factor controlling the ligand field and therefore the spin configuration of the Fe(II) atom. Nevertheless, more examples of closely related dinuclear and chain thiocyanato-bridged Fe(II) complexes containing a terminal thiocyanato ligand would be needed to confirm this assumption.

\section{- CONCLUSIONS}

We have prepared a new example of the uncommon Fe(II) 1-D coordination polymer. In this compound of formula $\left[\{\mathrm{Fe}(\mathrm{tpc}-\mathrm{OMe})(\mathrm{NCS})(\mu-\mathrm{NCS})\}_{\mathrm{n}}\right](\mathbf{1})$, the metal iron(II) ions are bridged by a single thiocyanato ligand acting with a $\mu-\kappa N: \kappa S-S C N$ bridging coordination mode, leading to a neutral zig-zag chain along the [010] direction. The $\mathrm{FeN}_{5} \mathrm{~S}$ polyhedron, arises from the coordination of the three pyridine nitrogen atoms of the tpc-OMe ligand, and from the two nitrogen and one sulphur atoms belonging to the two equivalent bridging and to the terminal thiocyanato ligands. The thermal variation of the $\chi_{M} T$ product shows abrupt and complete HS/LS transition at $199 \mathrm{~K}$ with a scan rate of $0.8 \mathrm{~K} / \mathrm{min}$. This behavior is in good agreement with the significant changes of the $\mathrm{FeN}_{5} \mathrm{~S}$ coordination sphere derived from the structural characterizations at room temperature and at $150 \mathrm{~K}$, and with the DSC studies for which the thermal variation of the heat flow indicated exo- and endo-thermic transitions at 198 and $199 \mathrm{~K}$, respectively. In order to confirm the cooperative character of the sharp magnetic transition, a detailed study of the hysteresis loop as a function of the scan rate clearly indicate the presence of two distinct transition temperatures in cooling and warming modes, with a significant dependence on the temperature scan rate. From the design and experimental point of views, this work shows slight chemical changes of the functional group $(\mathrm{R})$ of the tripodal ligand (tpc-OR) induce drastic changes in the structural and in the magnetic characteristics: the tpc-OH and tpc-Obn led to two dinuclear complexes $\left[\{\mathrm{Fe}(\mathrm{tpc}-\mathrm{OR})(\mathrm{NCS})(\mu-\mathrm{NCS})\}_{2}\right]$ exhibiting spin crossover behaviour $(\mathrm{R}=\mathrm{H}, 2){ }^{45}$ and ferromagnetic coupling $\left(\mathrm{R}=\mathrm{C}_{6} \mathrm{H}_{5}, 3\right)$, ${ }^{46}$ while the tpc-OMe ligand led to $\mathrm{Fe}(\mathrm{II})$ 1-D coordination polymer (1) with a cooperative SCO transition. Last but not least, these significant structural and electronic differences cannot be exclusively attributed to the nature of the sterically hindered functional group inducing structural deformation around the coordination sphere since the solid-state packing also can affect strongly the 
elastic and the magnetic interactions. ${ }^{54-57}$ In fact, experimental and MO extended Hückel calculations suggest that the almost linearity of the $\mathrm{N}$-bound terminal thiocyanato, which is promoted by the $\pi-\pi$ and weak C-H $\cdots S$ intermolecular interactions, plays a significant role in the observation of SCO behavior. It should be noted that this conclusion also confirmed a recent study on SCO mononuclear complexes, involving two $\mathrm{NCS}^{-}$ligands but different N-based neutral co-ligands, for which it has been shown that the linearity of the Fe-N-C angles favours the LS state of the $\mathrm{Fe}(\mathrm{II})$ centre. $^{58}$

\section{- EXPERIMENTAL SECTION}

General Procedures. All reagents were purchased from commercial sources and used without purifications. Solvents were distilled by standard procedures. The tris(2pyridyl)methoxymethane (tpc-OMe) molecule was synthesized as previously described (see Figure S1-S3). ${ }^{50}$

Preparation of $\left[\{\mathrm{Fe}(\mathbf{t p c}-\mathrm{OMe})(\mathrm{NCS})(\boldsymbol{\mu}-\mathrm{NCS})\}_{\mathbf{n}}\right]$ (1). To a solution of tris(2pyridyl)methoxymethane (tpc-OMe) $(138.4 \mathrm{mg}, 0.5 \mathrm{mmol})$ in $8 \mathrm{~mL}$ of EtOH was progressively added a methanolic solution $(8 \mathrm{~mL})$ of $\mathrm{FeCl}_{2} \cdot 4 \mathrm{H}_{2} \mathrm{O}(99.4 \mathrm{mg}, 0.5 \mathrm{mmol})$. Then a solution of potassium thiocyanate $(97.2 \mathrm{mg}, 1.0 \mathrm{mmol})$ in $10 \mathrm{~mL}$ of $\mathrm{MeCN}$ was slowly added under stirring. The resulting yellow solution gave polycrystalline yellow powder of 1 after two days at room temperature (yield. $168.5 \mathrm{mg}, 75 \%$ ). Anal. Calcd. for $\mathrm{C}_{19} \mathrm{H}_{15} \mathrm{FeN}_{5} \mathrm{OS}_{2}(\mathbf{1})$ : C, 50.7; N, 15.6; H, 3.3. Found: C, 50.9; N, 15.9; H, 3.4. IR data (ATR, v/cm ${ }^{-1}$ ) of 1 (see Figure S4a): 2104(s), 2069(s), 1593(m), 1461(s), 1434(m), 1204(m), 1157(m), 1131(m), 1100(m), 1082(s), 1013(m), 984(m), 783(m), 757(s), 658(s), 632(m), 633(m), 504(w), 473(m), 456(m), 424(s). Single-crystals of 1 were obtained by slow diffusion, in a glass tube $\left(3.0 \mathrm{~mm}\right.$ diameter) of two $\mathrm{CH}_{3} \mathrm{OH}$ solutions: the first one was prepared by dissolving $\mathrm{FeCl}_{2} .4 \mathrm{H}_{2} \mathrm{O}(45.7 \mathrm{mg}, 0.23 \mathrm{mmol})$ and tris(2pyridyl)methoxymethane $(63.0 \mathrm{mg}, 0.23 \mathrm{mmol})$ in $10 \mathrm{~mL}$, and the second one was obtained by dissolving KNCS (44.0 mg, $0.46 \mathrm{mmol}$ ) in $10 \mathrm{~mL}$. A volume of $2 \mathrm{~mL}$ of the first solution was placed in the glass tube $(3.0 \mathrm{~mm}$ diameter $)$ and $2 \mathrm{~mL}$ of the second solution was added carefully. After three weeks, yellow small fine plate crystals of $\mathbf{1}$ were formed by slow diffusion at room temperature. IR data (ATR, $v / \mathrm{cm}^{-1}$ ) of 1 (see Figure S4b): 2104(s), 2069(s), 1592(m), 1461(s), 1435(m), 1204(m), 1158(m), 1131(m), 
1100(m), 1082(s), 1014(m), 984(m), 783(m), 762(s), 670(m), 659(s), 644(m), 633(m), 504(w), 474(m), 424(m).

Physical Measurements. Infrared (IR) spectra were collected on a FT-IR BRUKER ATR VERTEX70 Spectrometer. ${ }^{1} \mathrm{H}$ and ${ }^{13} \mathrm{C}$ NMR spectra were recorded on Bruker AMX-500 spectrometer. DSC measurements were performed on a DSC-1/LN2 Mettler Toledo calorimeter. Magnetic and photomagnetic measurements were performed with a Quantum Design MPMS-XL-5 SQUID magnetometer in the 10-350 K temperature range. The theoretical MO extended-Hückel (MO-EH) calculations were performed by using hyperchem program $^{59}$ (See SI for details).

Crystallographic Data Collection and Refinement. Crystallographic study of compound 1 was performed at 296 and $150 \mathrm{~K}$. The crystallographic data have been collected on an Oxford Diffraction Xcalibur CCD diffractometer with Mo Ka radiation. Single crystal of $0.15 \times 0.04 \times 0.02 \mathrm{~mm}^{3}$ was used to collect the data. For both temperatures, the data collections were performed using $1^{\circ} \omega$-scans with an exposure time of $260 \mathrm{~s}$ per frame. The unit cell determinations and data reductions were performed using the CrysAlis program suite on the full set of data. ${ }^{60}$ The crystal structures were solved by direct methods and successive Fourier difference syntheses with the Sir97 program ${ }^{61}$ and refined on $F^{2}$ by weighted anisotropic full-matrix leastsquare methods using the SHELXL97 program. $^{62}$ All non-hydrogen atoms were refined anisotropically while the hydrogen atoms were calculated and therefore included as isotropic fixed contributors to $F_{\mathrm{c}}$. Due to the low absorption coefficient of 1 only semiempirical absorption correction was needed and performed by the multi-scan method. ${ }^{60}$ Crystallographic data including refinement parameters, bond lengths and bond angles are given in Tables S1 and S2, respectively. It should be noted that the small size of the single crystals of $\mathbf{1}$ did not allow an accurate data collection at room temperature. However, data collection with a relatively high exposure time (260 s per frame) led to correct structural data, in particular at low temperature $(150 \mathrm{~K})$. Room-temperature Xray powder diffraction spectrum (XRPD) was recorded on a PANalytical Empyrean Xray powder diffractometer at $45 \mathrm{kV}, 40 \mathrm{~mA}$ with a $\mathrm{Cu}$-target tube (Figure 3).

\section{ASSOCIATED CONTENT}

\section{Supporting information}


The Supporting Information is available free of charge on the ACS Publications website at DOI: XXXXX/acs.inorg-chem.XXXXXXX

X-ray crystallographic data in CIF format: CCDC number 1829376 and 1829377 (CIF). This material is available free of charge via the Internet at http://pubs.acs.org.

\section{AUTHOR INFORMATION}

\section{Corresponding author}

*E-mail: smail.triki@univ-brest.fr

\section{Author Contributions}

The manuscript was written through contributions of all authors.

Notes

The authors declare no competing financial interest.

\section{aCKNOWLEDGMENTS}

The authors acknowledge the CNRS (Centre National de la Recherche Scientifique), the "Université de Brest", the "Agence Nationale de la Recherche" (ANR project BISTAMAT: ANR-12-BS07-0030-01). AJM and EC thank the financial support from the Junta de Andalucía (FQM-195) and the Project of excellence P11-FQM-7756, MINECO of Spain (Project CTQ2014-56312-P) and the University of Granada. ST greatly thanks Prof. Takayuki Ishida from the University of Tokyo for having supplied us supplementary X-ray data concerning compound $[\{\mathrm{Fe}(\mathrm{tpc}-\mathrm{OH})(\mathrm{NCS})(\mu-$ $\left.\mathrm{NCS})\}_{2}\right](\mathrm{PrOH})_{2}(\mathbf{2})$. 


\section{Q REFERENCES}

(1) Halcrow, M. A. (Eds.), Spin-Crossover Materials, Properties and Applications, 2013, John Wiley \& Sons Ltd, Oxford, UK.

(2) Gütlich, P.; Goodwin, H. A. (Eds.) Top. Curr. Chem. 2004, 233-235, SpringerVerlag Berlin Heidelberg New York.

(3) Pittala, N.; Thétiot, F.; Triki, S.; Boukheddaden, K.; Chastanet, G.; Marchivie, M. Cooperative 1D Triazole-Based Spin Crossover $\mathrm{Fe}^{\mathrm{II}}$ Material With Exceptional Mechanical Resilience. Chem. Mater. 2017, 29, 490-494.

(4) Phan, H.; Hrudka, J. J.; Igimbayeva, D.; Lawson Daku, L. M.; Shatruk, M. A simple approach for predicting the spin state of homoleptic $\mathrm{Fe}(\mathrm{II})$ tris-diimine complexes. J. Am. Chem. Soc. 2017, 139, 6437-6447.

(5) Pittala, N.; Thétiot, T.; Charles, C.; Triki, S.; Boukheddaden, K.; Chastanet, G.; Marchivie, M. An unprecedented trinuclear Fe ${ }^{\mathrm{II}}$ triazole-based complex exhibiting a concerted and complete sharp spin transition above room temperature. Chem. Commun. 2017, 53, 8356-8359.

(6) Milin, E.; Patinec, V.; Triki, S.; Bendeif, E.-E.; Pillet, S.; Marchivie, M.; Chastanet, G.; Boukheddaden, K. Elastic Frustration Triggering Photoinduced Hidden Hysteresis and Multistability in a Two-Dimensional Photoswitchable Hofmann-Like Spin-Crossover Metal-Organic Framework. Inorg. Chem. 2016, 55, 11652-11661.

(7) Shatruk, M.; Phan, H.; Chrisostomo, B. A.; Suleimenova, A. Symmetry-breaking structural phase transitions in spin crossover complexes. Coord. Chem. Rev. 2015, 289-290, 62-73.

(8) Atmani, C.; El Hajj, F.; Benmansour, S.; Marchivie, M.; Triki, S.; Conan, F.; Patinec, V.; Handel, H.; Dupouy, G.; C. J. Gómez-García. Guidelines to design new spin crossover materials. Coord. Chem. Rev. 2010, 254, 1559-1569.

(9) Coronado, E.; Galán-Mascarós, J. R.; Monrabal-Capilla, M.; García-Martínez, J.; Pardo-Ibáñez, P. Bistable Spin-Crossover Nanoparticles Showing Magnetic Thermal Hysteresis near Room Temperature. Adv. Mater. 2007, 19, 1359-1361.

(10) Shalabaeva, V.; Ridier, K.; Rat, S.; Manrique-Juarez, M. D.; Salmon, L.; Séguy, I.; Rotaru, A.; Molnár, G.; Bousseksou, A. Room temperature current modulation in large area electronic junctions of spin crossover thin films. Appl. Phys. Lett. 2018, 112, 013301.

(11) Senthil Kumar, K.; Ruben, M. Emerging trends in spin crossover (SCO) based functional materials and devices. Coord. Chem. Rev. 2017, 346, 176-205.

(12) Dugay, J.; Giménez-Marqués, M.; Kozlova, T.; Zandbergen, H. W.; Coronado, E.; van der Zant, H. S. J. Spin switching in electronic devices based on 2D assemblies of spin-crossover nanoparticles. Adv.Mater. 2015, 27, 1288-1293.

(13) Jeon, I.-R.; Park, J. G.; Haney, C. R.; Harris, T. D. Spin crossover iron(II) complexes as PARACEST MRI thermometers. Chem. Sci. 2014, 5, 2461-2465.

(14) Baadji, N.; Sanvito, S. Phys. Rev. Lett. 2012, 108, 217201. Giant resistance change across the phase transition in spin-crossover molecules.

(15) Prins, F; Monrabal-Capilla, M; Osorio, E.A.; Coronado, E; van der Zant, H. S. J. Room-temperature electrical addressing of a bistable spin-crossover molecular system. Adv. Mater. 2011, 23, 1545-1549.

(16) Bousseksou, A.; Negre, N.; Goiran, M.; Salmon, L.; Tuchagues, J. P.; Boillot, M. L.; Boukheddaden, K.; Varret, F. Dynamic triggering of a spin-transition by a pulsed magnetic field. Eur. Phys. J. B. 2000, 13, 451-456. 
(17) Bousseksou, A.; Molnár, G.; Salmon, L.; Nicolazzi, W. Molecular spin crossover phenomenon: recent achievements and prospects. Chem. Soc. Rev. 2011, 40, 3313-3335.

(18) Gütlich, P.; Goodwin, H. A. Spin Crossover in Transition Metal Compounds I-III. Springer-Verlag Berlin Heidelberg: Berlin, Heidelberg, New York, 2004; Vol. 233, 234, 235.

(19) Linares, J.; Codjovi, E.; Garcia, Y. Pressure and temperature spin crossover sensors with optical detection. Sensors 2012, 12 (4), 4479-4492.

(20) Gutlich, P.; Gaspar, A. B.; Garcia, Y. Spin state switching in iron coordination compounds. Beilstein J. Org. Chem. 2013, 9, 342-391.

(21) Jureschi, C.-M.; Linares, J.; Boulmaali, A.; Dahoo, P. R.; Rotaru, A.; Garcia, Y. Pressure and Temperature Sensors Using Two Spin Crossover Materials. Sensors 2016, 16, 187.

(22) Boinnard, D.; Bousseksou, A.; Dworkin, A.; Savariault, J.-M.; Varret, F.; Tuchagues, J.-P. Two-step spin conversion of $\left[\mathrm{Fe}^{\mathrm{II}}\left(5-\mathrm{NO}_{2}\right.\right.$-sal-N(1,4,7,10))]: 292, 153 , and $103 \mathrm{~K} \mathrm{X}$-ray crystal and molecular structure, infrared, magnetic, Mössbauer, calorimetric, and theoretical studies. Inorg. Chem. 1994, 33, 271-281.

(23) Lochenie, C.; Bauer, W.; Railliet, A. P.; Schlamp, S.; Garcia, Y.; Weber, B. Large Thermal Hysteresis for Iron(II) Spin Crossover Complexes with $N$-(Pyrid-4yl)isonicotinamide. Inorg. Chem. 2014, 53, 11563-11572.

(24) Bauer, W.; Schlamp, S.; Weber, B. A ladder type iron(II) coordination polymer with cooperative spin transition. Chem. Commun. 2012, 48, 10222-10224.

(25) Weber, B.; Kaps, E. S.; Obel, J.; Achterhold, K.; Parak, F. G. Synthesis and Characterization of a Dinuclear Iron(II) Spin Crossover Complex with Wide Hysteresis. Inorg. Chem. 2008, 47, 10779-10787.

(26) Weber, B.; Kaps, E.;Weigand, J.; Carbonera, C.; Létard, J.-F.; Achterhold, K.; Parak, F. G. Cooperative Iron(II) Spin Crossover Complexes with $\mathrm{N}_{4} \mathrm{O}_{2}$ Coordination Sphere. Inorg. Chem. 2008, 47, 487-496.

(27) Weber, B.; Carbonera, C.; Desplanches, C.; Létard, J.-F. Stepwise Spin Transition in a Mononuclear Iron(II) Complex with Unusually Wide Plateau. Eur. J. Inorg. Chem. 2008, 10, 1589-1598.

(28) Weber, B.; Kaps, E. S.; Desplanches, C.; Létard, J.-F.; Achterhold, K.; Parak, F. G. Synthesis and Characterisation of two new Iron(II) Spin-Crossover Complexes with $\mathrm{N}_{4} \mathrm{O}_{2}$ Coordination spheres - Optimizing Preconditions for Cooperative Interactions. Eur. J. Inorg. Chem. 2008, 31, 4891-4898.

(29) Weber, B.; Bauer, W.; Obel, J. An Iron(II) Spin Crossover Complex with a $70 \mathrm{~K}$ Wide Thermal Hysteresis Loop. Angew. Chem., Int. Ed. 2008, 47, 10098-10101.

(30) Iasco, O.; Rivière, E.; Guillot, R.; Buron-Le Cointe, M.; Meunier, J.-F.; Bousseksou, A.; Boillot, M.-L. Fe ${ }^{\mathrm{II}}\left(\text { pap- }-5 \mathrm{NO}_{2}\right)_{2}$ and Fe $(\mathrm{II} \text { (qal-5NO})_{2}$ Schiff-Base Spin-Crossover Complexes: A Rare Example with Photomagnetism and RoomTemperature Bistability. Inorg. Chem. 2015, 54, 1791-1799.

(31) Zhang, L.; Xu, G.-C.; Xu, H.-B.; Mereacre, V.; Wang, Z.-M.; Powell, A.-K.; Gao, S. Synthesis, magnetic and photomagnetic study of new iron(II) spin-crossover complexes with $\mathrm{N}_{4} \mathrm{O}_{2}$ coordination sphere. Dalton Trans. 2010, 39, 4856-4868.

(32) Kuroda-Sowa, T.; Senzaki, Z.; Yu, Y.; Sugimoto, K.; Maekawa, M.; Munakata, M.; Hayami, S.; Maeda, Y. Abrupt Spin Transitions and LIESST Effects Observed in $\mathrm{Fe}^{\mathrm{II}}$ Spin-crossover Complexes with Extended $\pi$-Conjugated Schiffbase Ligands Having $\mathrm{N}_{4} \mathrm{O}_{2}$ Donor Sets. Chem. Lett. 2008, 37, 1216-1217.

(33) Wang, Q.; Venneri, S.; Zarrabi, N.; Wang, H.; Desplanches, C.; Letard, J.-F.; Seda, T.; Pilkington, M. Stereochemistry for engineering spin crossover: 
structures and magnetic properties of a homochiral vs. racemic $\left[\mathrm{Fe}\left(\mathrm{N}_{3} \mathrm{O}_{2}\right)(\mathrm{CN})_{2}\right]$ complex. Dalton Trans. 2015, 44, 6711-6714.

(34) Wang, H.; Desplanches, C.; Dagault, P.; Letard, J.-F. A new family of diamagnetic macrocyclic $\mathrm{Fe}(\mathrm{II})$ compounds exhibiting the LIESST effect at high temperatures. Dalton Trans. 2014, 43, 15346-15350.

(35) Costa, J. S.; Balde, C.; Carbonera, C.; Denux, D.; Wattiaux, A.; Desplanches, C.; Ader, J.-P.; Gütlich, P.; Létard, J.-F. Photomagnetic Properties of an Iron(II) LowSpin Complex with an Unusually Long-Lived Metastable LIESST State. Inorg. Chem. 2007, 46, 4114-4119.

(36) Costa, J.S.; Guionneau, P.; Létard, J.-F. Photomagnetic properties of the $\left[\mathrm{Fe}\left(\mathrm{L}_{222}\left(\mathrm{~N}_{3} \mathrm{O}_{2}\right)\right)(\mathrm{CN})_{2}\right] \cdot \mathrm{H}_{2} \mathrm{O}$ complex: a fascinating example of multimetastability. J. Phys.: Conf. Series, 2005, 21, 67-72.

(37) Nelson, S. M.; Mcllroy, P. D. A.; Stevenson, C. S. Quadridentate versus Quinquedentate Co-ordination of some N, and N,O, Macrocyclic Ligands and an Unusual Thermally controlled Quintet $\leftrightarrow$ Singlet Spin Transition in an Iron(II) Complex. J. Chem. Soc., Dalton Trans. 1986, 991-995.

(38) Holzhacker, C.; Calhorda, M. J.; Gil, A.; Carvalho, M. D.; Ferreira, L. P.; Stöger, B.; Mereiter, K.; Weil, M.; Müller, D.; Weinberger, P.; Pittenauer, E.; Allmaier, G.; Kirchner, K. Six-coordinate high-spin iron(II) complexes with bidentate PN ligands based on 2-aminopyridine - new Fe(II) spin crossover systems. Dalton Trans. 2014, 43, 11152-11164.

(39) König, E.; Ritter, G.;Goodwin, H. A. ${ }^{57}$ Fe Mössbauer effect study of a presumed singlet-triplet transition in $\left[\mathrm{Fe}(\mathrm{P})_{4} \mathrm{X}\right] \mathrm{BPh}_{4}$ complexes, $\mathrm{X}=\mathrm{Br}$, I. Chem. Phys. Lett. 1975, 31, 543-546.

(40) Rosa, P.; Debay, A.; Capes, L.; Chastanet, G.; Bousseksou, A.; Le Floch, P.; Létard, J.-F. Eur. J. Inorg. Chem., 2004, 3017-3019.

(41) Yergeshbayeva, S.; Hrudka, J. J.; Lengyel, J.; Erkasov, R.; Stoian, S. A.; Dragulescu-Andrasi, A.; Shatruk, M. Heteroleptic Fe(II) Complexes with $\mathrm{N}_{4} \mathrm{~S}_{2}$ Coordination as a Platform for Designing Spin-Crossover Materials. Inorg. Chem. 2017, 56, 11096-11103.

(42) Arroyave, A.; Lennartson, A.; Dragulescu-Andrasi, A.; Pedersen, K. S.; Piligkos, S.; Stoian, S. A.; Greer, S. M.; Pak, C.; Hietsoi, O.; Phan, H.; Hill, S.; McKenzie, C. J.; Shatruk, M. Spin Crossover in Fe(II) Complexes with $\mathrm{N}_{4} \mathrm{~S}_{2}$ Coordination. Inorg. Chem. 2016, 55, 5904-5913.

(43) Hogue, R. W.; Feltham, H. L. C; Miller, R. G.; Brooker, S. Spin Crossover in Dinuclear $\mathrm{N}_{4} \mathrm{~S}_{2}$ Iron(II) Thioether-Triazole Complexes: Access to [HS-HS], [HSLS], and [LS-LS] States. Inorg. Chem. 2016, 55, 4152-4165.

(44) Lennartson, A.; Bond, A. D.; Piligkos, S.; McKenzie, C. J. Four-Site Cooperative Spin Crossover in a Mononuclear $\mathrm{Fe}^{\mathrm{II}}$ Complex. Angew. Chem. Int. Ed. 2012, 51, 11049-11052.

(45) Yamasaki, M.; Ishida, T. First Iron(II) Spin-crossover Complex with an $\mathrm{N}_{5} \mathrm{~S}$ Coordination Sphere. Chem. Lett. 2015, 44, 920-921.

(46) Mekuimemba, C. D.; Conan, F.; Mota, A. J.; Palacios, M. A.; Colacio, E.; Triki, S. On the Magnetic Coupling and Spin Crossover Behavior in Complexes Containing the Head-to-Tail $\left[\mathrm{Fe}^{\mathrm{II}}{ }_{2}(\mu-\mathrm{SCN})_{2}\right]$ Bridging Unit: A Magnetostructural Experimental and Theoretical Study. Inorg. Chem. 2018, 57, 2184-2192.

(47) Pohl, K.; Wieghardt, K.; Nuber, B.; Weiss, J. Preparation and Magnetism of the Binuclear Iron(II) Complexes $\left[\left\{\mathrm{Fe}\left(\mathrm{C}_{9} \mathrm{H}_{21} \mathrm{~N}_{3}\right) \mathrm{X}_{2}\right\}_{2}\right](\mathrm{X}=\mathrm{NCS}, \mathrm{NCO}$, or $\mathrm{N})$ and their Reaction with NO. Crystal Structures of $\left[\left\{\mathrm{Fe}\left(\mathrm{C}_{9} \mathrm{H}_{21} \mathrm{~N}_{3}\right)(\mathrm{NCS})_{2}\right\}_{2}\right]$ and $\left[\mathrm{Fe}\left(\mathrm{C}_{9} \mathrm{H}_{21} \mathrm{~N}_{3}\right)(\mathrm{NO})\left(\mathrm{N}_{3}\right)_{2}\right]$. J. Chem. Soc., Dalton Trans. 1987, 187-192. 
(48) Salaudeen, A. A.; Kilner, C. A.; Halcrow, M. A. Mononuclear and dinuclear iron thiocyanate and selenocyanate complexes of tris-pyrazolylmethane ligands. Polyhedron 2008, 27, 2569-2576.

(49) McQuilken, A. C.; Jiang, Y.; Siegler, M. A.; Goldberg, D. P. Addition of dioxygen to an $\mathrm{N}_{4} \mathrm{~S}$ (thiolate) iron(II) cysteine dioxygenase model gives a structurally characterized sulfinato-iron(II) complex. J. Am. Chem. Soc. 2012, 134, 8758-8761.

(50) Jonas, R. T., M.; Stack, T. D. P. Synthesis and Characterization of a Family of Systematically Varied Tris(2-pyridyl)methoxymethane Ligands: Copper(I) and Copper(II) Complexes. Inorg. Chem. 1998, 37, 6615-6629.

(51) Guionneau, P.; Marchivie, M.; Bravic, G.; Létard, J.-F.; Chasseau, D., Top. Curr. Chem. 2004, 234, 97.

(52) Kabesova, M.; Gazo, J. Structure and classification of thiocyanates and the mutual influence of their ligands. Chcm. Zvesti 1980, 34, 800-841.

(53) Kahn, O.; in Molecular Magnetism, 1993, Wiley-VCH (Eds), 53-86.

(54) Milin, E.; Benaicha, B.; El Hajj, F.; Patinec, V.; Triki, S.; Marchivie, M.; GomezGarcia, C.-J.; Pillet, S. Magnetic Bistability in Macrocycle-Based Fe ${ }^{\text {II }}$ SpinCrossover Complexes: Counter Ion and Solvent Effects. Eur. J. Inorg. Chem.2016, 5305-5314.

(55) J. Tao, J.; Wei, R.-J.; Huang, R.-B.; Zheng, L.-S. Polymorphism in spin-crossover systems. Chem. Soc. Rev.2012, 41, 703-737.

(56) Wei, R.-J.; Li, B.; Tao, J.; Huang, R.-B.; Zheng, L.-S.; Zheng, Z. Making SpinCrossover Crystals by Successive Polymorphic Transformations. Inorg. Chem. 2011, 50, 1170-1172.

(57) Li, B.; Wei, R.-J.; Tao, J.; Huang, R.-B.; Zheng, L.-S.; Zheng, Z. Solvent-Induced Transformation of Single Crystals of a Spin-Crossover (SCO) Compound to Single Crystals with Two Distinct SCO Centers. J. Am. Chem. Soc. 2010, 132, 1558-1566.

(58) Smeets, V.; Wolff, M.; Wolny, J. A.; Schünemann, V.; Dîrtu, M. M.; Ge, J.-Y.; Vanacken, J.; Moshchalkov, V.; Garcia, Y. Spin State Crossover, Vibrational, Computational, and Structural Studies of $\mathrm{Fe}^{\mathrm{II}}$ 1-Isopropyl-1H-tetrazole Derivatives. Eur. J. Inorg. Chem. 2018, 394-413.

(59) HyperChem 5, Hypercube Inc.: Gainesville, FL, 1997.

(60) Oxford Diffraction (2006). Xcalibur CCD/RED CrysAlis Software system. Oxford Diffraction Ltd, Abingdon, England.

(61) Altomare, A.; Burla, M. C.; Camalli, M.; Cascarano, C.; Giacovazzo, C.; Guagliardi, A.; Moliterni, A. G. G.; Polidori, G.; Spagna, R. SIR97: a new tool for crystal structure determination and refinement. J. Appl. Cryst. 1999, 32, 115-119.

(62) Sheldrick, G. Crystal structure refinement with SHELXL. Acta Cryst. C 2015, 71, 3-8. 


\section{For Table of Contents Only}

\section{TOC synopsis}

\section{One-dimensional Thiocyanato-Bridged Fe(II) Spin Crossover Cooperative Polymer With Unusual FeN $\mathrm{N}_{5} \mathrm{~S}$ Coordination Sphere}

Kahina Nebbali, Cle Donacier Mekuimemba, Catherine Charles, Guillaume Chastanet, Antonio J. Mota, Enrique Colacio, Smail Triki.

A new cooperative $\mathrm{Fe}(\mathrm{II})$ spin crossover ( $\mathrm{SCO}$ ) coordination polymer, with a single end-to-end thiocyanato bridges and an unusual $\mathrm{FeN}_{5} \mathrm{~S}$ coordination sphere, has been described. Experimental and theoretical investigations showed that the linearity of the N-bound terminal thiocyanato ligand plays a significant role in the presence of the SCO transition.

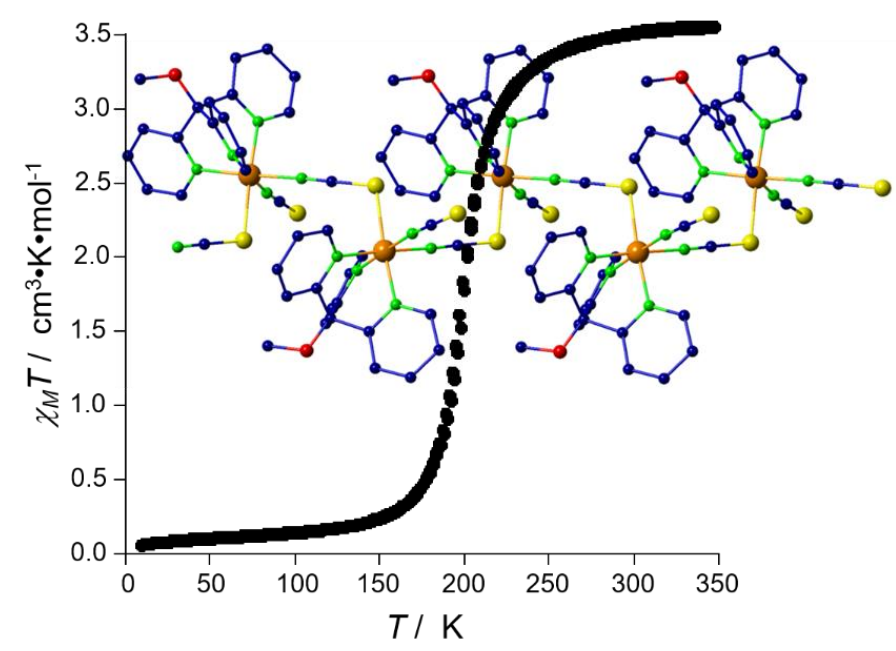

